\title{
RIVER ECOSYSTEM SERVICE IN SETTLEMENT DEVELOPMENT AND HISTORY OF COASTAL BANGLADESH: A CASE STUDY ON KACHUA UPAZILLA
}

\author{
Noor A. MD. Amanat Ullah* \\ Shibu Prasad Bosu**
}

\begin{abstract}
In Bangladesh every single settlement, whether it is urban or rural is situated alongside a form of inland water network. Livelihood, culture and civilization of these settlements maintain an intrinsic relationship with the GangaBrahmaputra-Meghna River Basin System. Inland water eco-system service plays a significant role in the establishment of a settlement and its socio-economic activities. The traditional role of the water network has however, deteriorated over the years due to the lack of ecological knowledge, dearth of proper strategies and policy guidelines and various anthropogenic activities in the face of accelerated climate change scenarios. This study attempts to find out the ecosystem services of Bhiarab River in the context of the national river management strategies and policies in cooperation with river-dependent community and challenges thereof. The paper explains the background of this River's channel-based navigation, along with the discussion of issues and challenges faced by the settlements. The findings reveal various strategic policies that have been implemented over the years on piecemeal basis to manage water resources, which did not end up well due to the absence of a holistic approach. It is suggested in this paper that future management plans for this River should involve local communities to avail their willingness to conserve the River, while making them resilient against anthropogenic and natural impacts through enhancement of socio-economic outputs from it. The community willingness and its dependence, as unearthed in this research, provides compelling ground for the authors to state that integrated planning with proper respect for local ecology is a mandatory strategic element for successful implementation of the policies in this regard.
\end{abstract}

Keywords: Coastal Settlement, River Ecosystem, River Management, National Policies, Structural Development

\section{INTRODUCTION}

A river is often regarded as life-blood of human settlements. It provides necessary support to the basic functions of life, such as drinking, washing, agriculture and industrial production. The life and culture of people in Bangladesh is intertwined with Ganga- Brahmaputra-Meghna (GBM) River Basin System. This river network has however, changed its course from time to time (Rudra, 2018). As a general thumb rule, the average human settlement density within fifty kilometers of the coast is higher in large river basins than in smaller coastal basins (Fang et al., 2018). Coastal riverbased settlements were usually established for reasons of accessibility, navigation control, trade and agriculture. Historically there tends to be a symbiotic relationship between these settlements and their associated river ecosystem. The South West region of Bangladesh is unique in nature with its brackish water ecosystem interspersed with sensitive tide-dominated rivers, water-filled depressions and streams. The system of the river of this region is altered due to national policies and strategies implemented from time to time and now this age old river system is taking its toll by damaging settlements, agriculture, transport and disaster management system (Dempster and Brummer, 1992).

This study has taken Bhairab River in Kachua Upazilla as a case study to review ongoing process of rationalization of national policies within the historical connotations related to river management in South West coast of Bangladesh. These policies are being implemented on the basis of national priorities, perception of the local and on the basis of environmental auditing. Various aspects of targeted and achieved objectives are given priority, following the functionalities of national policies.

\footnotetext{
* Noor A. MD, Amanat Ullah, GIS Analyst and Research Coordinator, Bose and Partners, Khulna, Bangladesh. Email Correspondence: namanatullah@gmail.com

** Shibu Prasad Bosu, Assistant Profesor, Khulna University, Khulna, Bangladesh.
} 


\section{STUDY AREA}

Bhairab River has played a dominant role in the development of settlements in Kachua Upazilla. Over time, people have grown and adapted to the natural characteristics of this water system and its fluid landscapes. Locals have used this physical environment in different ways to gain advantage in trade, communication and production. Climate, life style, and geomorphology of this region have produced different responses. The cultural practices have also impacted the settlements eventually creating distinctive settlement forms that may be described as the defining patterns or cultural products of historically- developed coastal river- based civilizations (Figure 1).

\section{METHODS}

The study includes interpretive historical research and case studies. The research relies on a range of research methods which range from qualitative questionnaire survey of local residents to semi structured interviews of various actors from the realms of policy, design and planning; an analysis of relevant mouza maps (both cadastral survey and revised survey are included), satellite imagery (Landsat-5 WRS-2 and Landsat $7 \mathrm{TM}$ ) and shapefiles by ArcGIS 10.4. and Erdas Imagine 2014.

\section{History: An Overview of National River Management Policy}

For millions of years GBM carried sediments from Himalayan mountain range, which forms the largest deltaic plan of the world- Bangladesh. From the beginning of time locals had to negotiate with this River network for settling in this region. In pre-colonial time, farmers used to collect levies from riverine crafts over the water course as per instruction from 'zamindars' or local landlords. During the colonial period the system continued and only the "Lords" were changed. After the end of the colonial rule, the government authorities took control over river management. The main objective of these authorities was to ensure maximum agricultural production and minimum damage due to natural calamity. River management planning has changed over time according to socio-economic needs (GED, 2018). The different phases of water resources planning processes and its main features are described in the following sections.

\section{Initial Phase: Krug Mission}

Krug Mission Report (1959) is the first major study which addressed the problem of flood control and water resources

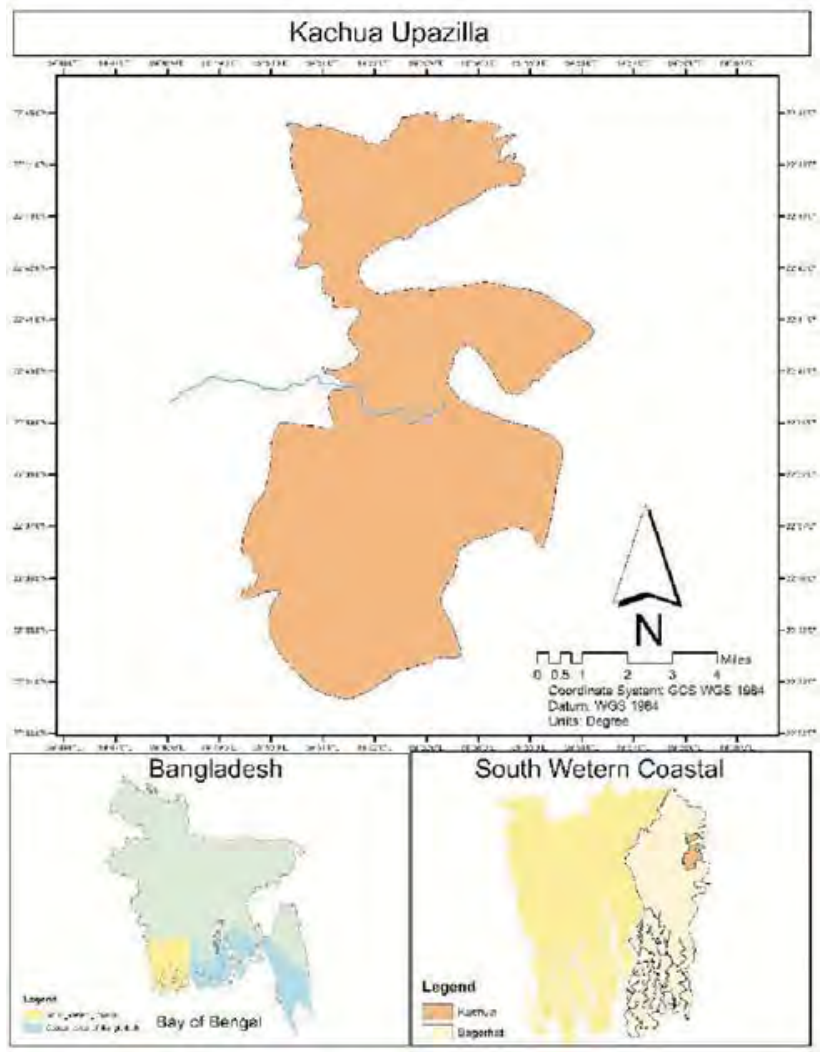

Figure-1: Study Area.

development of the country. Based on the recommendations of the Krug Mission, East Pakistan Water and Power Development Authority (EPWAPDA) installed a structural solution in the South West tidal areas called polder (circular embankment), for protecting land from flood inundation and saline intrusion. The report of the Krug Mission effectively discussed the principles governing delta development by large rivers and had various recommendations, suggestions and observations. It introduced the 'polder' enclosure system, a Dutch term (EPWAPDA, 1968).

\section{IECO Master Plan}

The main focus of IECO Master Plan (1964) was on development of the drainage system and on developing a proposal for flood control in the area. The plan also focused on developing the irrigation system in the area, albeit in a limited way. Following the Plan, the construction drainage and irrigation of large flood controlling projects, began in earnest. The objective of that plan was to protect the area from flooding and coastal storm surges, and eventually protect the agricultural produce (Ahmad, 2019; Ahmed, Choudhury, \& Ahmed, 2017). 


\section{NWP Phase}

The first National Water Plan (NWP-I) (1989) was based on various numerical models and many analytical tools were developed as part of this Phase. These were meant to define and suggest planning strategies. Both the NWP I and II Phases, emphasized on minor irrigation with low lift pump and shallow tube wells. It was recognized in these plans that fisheries are an important part of the income generation, and thus the plans recommended improvement in the design of water control structures. The objective behind this was to provide for fish migration. Several basic policies were proposed to strengthen the institution of fisheries. Improvement in the management of the FCDI projects was also proposed as part of this Plan, with the objective of enhancing fish production. Furthermore, the Plan also emphasized the requirement of setting aside some water bodies for fisheries development (Hossain, 2016).

\section{FAP Phase}

A number of projects were selected under Flood Action Plan (1989) which addressed the aforementioned problems and issues. Short-term projects addressed problems where there was clearly a need for early action, and medium to longterm projects included those which the regional studies showed generation of significant social and economic benefits, while causing least damage to the environment (Custers, 1993).

\section{NWMP Phase}

National Water Management Plan (2004) provided the policy directions for fisheries, industry, agriculture, navigation, environment, basin-wide planning, public and private investment, water rights and allocations, water supply and sanitation. The policy underscored the logistic utilization and larger principles of water resource development. It emphasized both private and public actions and highlighted the importance of conjunctive use of surface and ground water (WARPO, 2004a).

\section{Coastal Zone Policy and Strategy}

Coastal Zone Policy (2005) was developed, for implementing the policy, as to select strategic priorities and actions on the creation of the institutional environment that would enable the government to embark on a continuous and structured process of prioritization and the development and implementation of interventions for the development of the coastal zone (Ahmad, 2019).

\section{Master Plan for Haor Area}

The overall goal of the Master Plan for Haor area (2012) was to achieve sustainable development by integrated planning and implementation, through multi organizational involvement and community participation, for optimum utilization of resources and reduction of poverty. To be more precise, integrated development would comprise mainly flood management, environmental sustainability, production of crop, fisheries and livestock expansion of education, settlement and health facilities, road communication, navigation, water supply and sanitation, industry, afforestation and generation of power and energy (CEGIS, 2012).

\section{National Water Act}

National Water Act (2013) formulated policies and guidelines for integrated development, sustainable use, equitable distribution and conservation of water resources (GOB, 2013).

\section{Participatory Water Management Act}

Participatory Water Management Act (2014) gave direction for maintaining Participatory Water Management in the following sectors, (i) Participatory water management definition and process; (ii) Definition of stakeholder, beneficiaries and PAPs, (iii) Legal authority of WMO, (iv) Structure, function and responsibilities of different level of organogram of WMO, (v) Membership process and registration process and (vi) financial control and auditing process (Dewan, Buisson, \& Mukherji, 2014).

\section{BDP 2100}

In the Bangladesh Delta Plan 2100 (2018) the main focus was given to the role of Bangladesh Water Development Board, the Water Resource Planning Organization, Local Government and Engineering Department and Bangladesh Agricultural Development Corporation in water resources development planning (GED, 2018).

\section{IMPACTS OF RIVER MANAGEMENT POLICIES}

River Management' refers to national and regional development intrinsically associated with river ecosystem. The term defines a concept of making, in which both natural and manmade water systems are integrated in the process of development. Impacts on settlement development of Kachua Upazilla, for the adopted national polices and projects, used to manage Bhairab River and are described in following sections: 


\section{Settlement Pattern and Cultural Tradition}

Prior to post-colonial period River Bhairab was managed by local communities and they would build temporary earthen embankments to control the water. But there were three devastating floods in the 1950s, after which the installation of a large number of polder dykes was undertaken by the government authorities. Siltation in channel beds due to these projects resulted in shrinkage of River Bhairab, and after the installation of the switch under the Tidal River Management (TRM) Project, the flow of Bhairab was fortified to a great extent.

In the early stage, the settlers of this Region made canal network surrounding the River as the foci of nuclear pattern settlements (Figure 2a). These canals were used as a defense mechanism for the safety of households against flood. Even after the Krug Mission and IECO Master Plan projects, lands would get inundated in monsoon flood and people used canals as an adaptation process. Due to TRM projects, flood risks were reduced and people started settling beside rivers linearly (Figure $2 b$ ). Intrusion of road infrastructural development by LGED and RHD without respecting the canal-based settlement ecology also triggered road side ribbon development (Figure 2c). All these alterations in the water network of this region deteriorated the relationship of water and human settlements.



Figure-2b: Change in Human Settlement Pattern.
The Bhairab River had significant impact on the cultural and traditional development of Kachua Upazilla. A sport called 'Nouka Baich' was a part of the cultural tradition of this region, which is now extinct due to the fortification of the river water. Dwellers used to arrange local swimming competitions, which cannot be arranged any more. Reduction of these cultural events have great impacts on the psychology of new generation.

Furthermore, there are economic impacts also. For example, a group of people used to catch fish coming from the river through the canals and made their living in this region have now migrated to other regions for survival. People who earned their living by the blessings of the River are now unemployed and have been forced to migrate to urban areas in search of a livelihood. Many people have also opted for living on the roadside and on the embankments. A collective

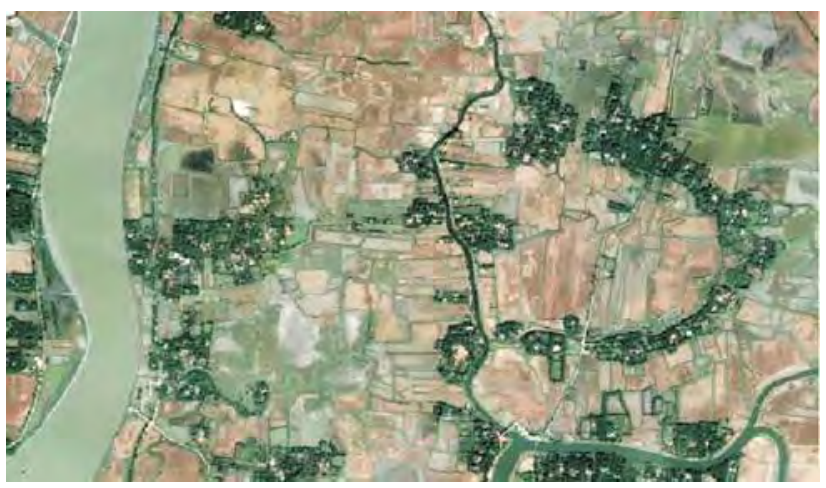

Figure-2a: Change in Human Settlement Pattern.

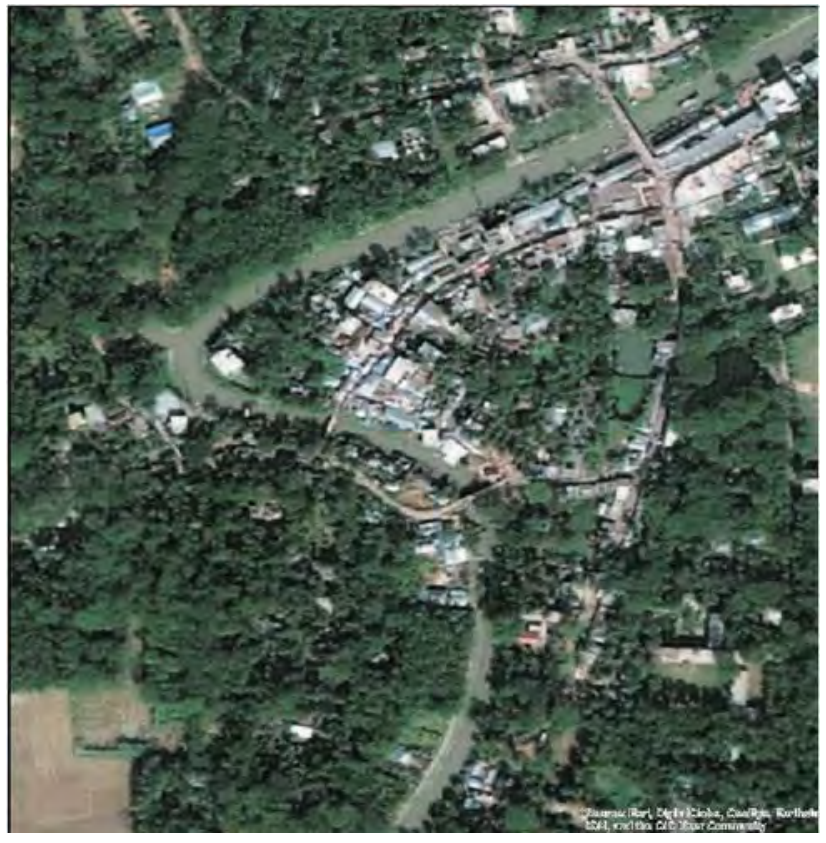

Figure-2c: Change in Human Settlement Pattern. 
impact is felt in terms of competition for the diminishing resources which is heightening conflicts and giving rise to tensions between different sectors of the society. This is resulting in the creation of an overall volatile social situation (Hoque, Quinn \& Sallu, 2018).

\section{Agriculture}

Prior to post-colonial period the local practice of 'Dosher Badh' (Community embankment) and 'Oshtadoshi Badh' (eight months embankment) was enrooted within the community. The embankments were made by temporary earthen materials, using low dykes and wooden sluice gates around the area. This was meant to protect the arable land from saline water intrusion and allow water to enter in the monsoon when salinity in the river was low. Thus, the farmers enjoyed good harvests in the dry period and a variety of fish in the monsoon. Due to flood mitigation, the government authorities started installing dykes and emphasized on increasing agricultural productivity in this region. The plan worked well till 1980's and resulted in high amount of rice production.

But as the international price of shrimp rose, saline water was allowed to enter and convert croplands into shrimp farming land. In areas where previously embankments were installed to protect crop lands, they were turned into large shrimp ghers (farms) forcibly. Thus, extensive shrimp farming changed the crop pattern of this region drastically (Ahmed, 2011).

As crop production reduced drastically, cattle industry faced a significant threat. Grazing land for cattle was converted into ghers and due to shortage of fodder people lost interest

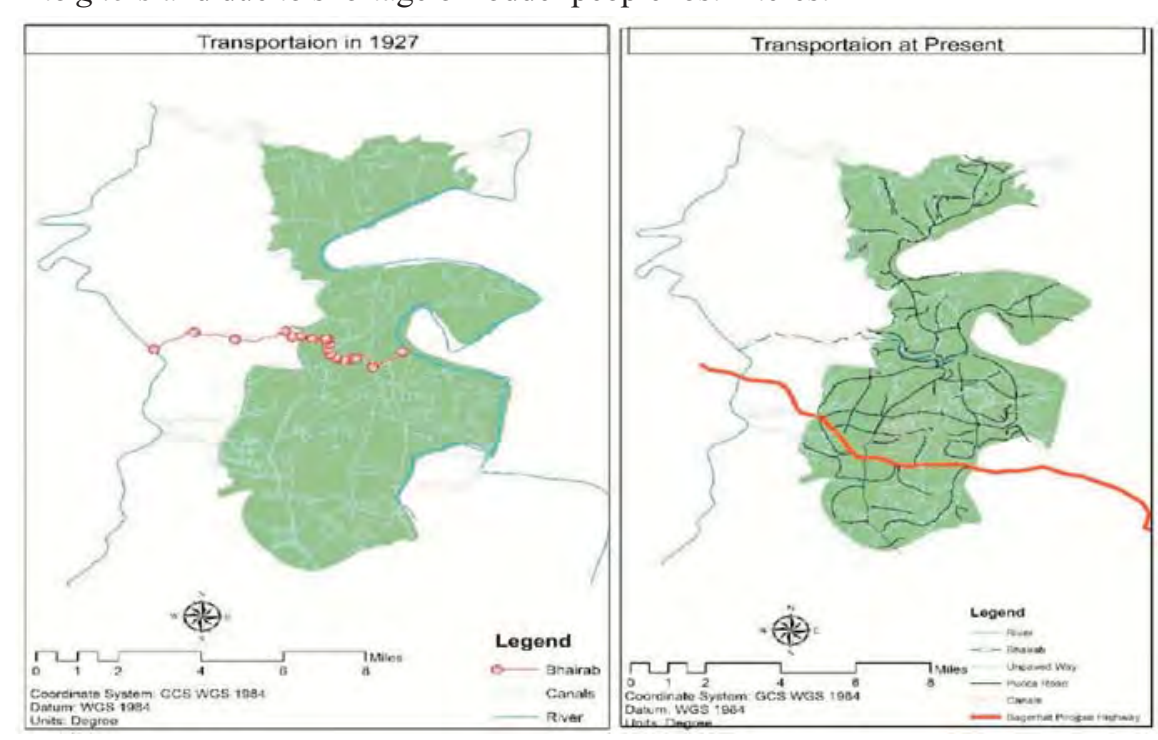

Figure-3: Transformation in Transportation System of Kachua Upazilla. in cattle farming.

Traditionally this region was famous for betel-nut production in large scale. Almost all the homestead gardens were full of betel-nut trees. Biggest betel-nut market of the country resided in Bagerhat and Kachua. Due to increase in salinity the production of betel-nut is degrading and this industry is now on the verge of extinction. People are now opting for options of trees which can survive in the saline water.

\section{Transport}

Bhairab River-based canal network navigation played a big part in the development of settlements in Kachua Uapzilla. This canal network not only served regionally but also extended its service nationally. Pirojpur district of Barisal division and Bagerhat district of Khulna division were connected through the Baleshwar-Bhairab-Doratan channel. It used to be the main route of communication between these two inter-divisional districts, prior to the installation of Bagehrat-Pirojpur highway road. Many drainage canals became inoperative due to siltation, Before the TRM sluice gates installation on River Bhairab, the River had an average width of eight hundred and eightyfive feet along the Kachua channel. Now the average width of the River is fifty feet, which turns it into a canal and unfit for large scale water navigation. The policy of connecting Bagerhat-Pirojpur via road network ignoring the water-based navigation has lessened the significance of Kachua as an intermediate region. Local businesses are facing serious trouble to establish a market place and this is in turn hindering the development of Kachua Upazila (Figure 3). 


\section{Drainage Management}

Since 1980s, the polders have become a serious concern for the drainage system. Today, a large amount of land has gone under water because of the siltation caused by the polders in the channel bed of the River. As there is no adequate maintenance and system for dredging in place, therefore the situation is getting worsened with each day passing by. Many of the structures and the polders block huge amounts of monsoon flood flows. This results in the overflowing monsoon water going upstream because of the polder embankment, which results in widespread flooding. This in turn results in large amounts of silt being deposited in the river channels and the river bed. This results in a reduced bulk-carrying capacity of the water in the channels and the River. This further leads to flooding as the drains get congested.

\section{CONCLUSION AND RECOMMENDATION}

River management policies and projects should change their focus on higher rice production in coastal zones as it is hampering the existing sustainable structure of river ecologybased livelihoods. There has been a shift in water policy concepts. As a result of this shift, multiple objective planning was promoted as compared to single-objective planning. The South West Area Integrated Water Resources Management Project (WARPO, 2004b) outlined the effects of disturbing the natural river ecosystem. Research studies on a national level, such as those done by the Department of Fisheries (Department of Fisheries, 2017), the Bangladesh Water Development Board and the Water Resources Planning Organization, have identified that structural interventions disrupting the floodplains are depriving the River from its resources. Multiple objective based national river plans have failed to understand the River's ecosystems (Uddin, 2005; Sanwar, 2010). Lack of proper vision and one dimensional planning and policies are making the region prone to disaster. Public sector institutional weakness and their inefficiency to impend according to proper planning is the reason behind dying rivers and the negative impact on the socio-economic activities related to the river system.

It is apparent from the above discussion that national river management policies, in a river ecosystem, for coastal settlements like Kachua Upazilla, have major negative consequences. However, the people want amalgamation of nature and human activities to utilize this natural blessing properly. Previously all the plans and policies implemented by the management heavily damaged economic and social aspects of local communities living on the banks of the River. This was partly because of the lack of appreciation and understanding of locals, and partly because of the lack of a holistic understanding of the water system and it's ecology on the part of the government. Therefore, it is recommended to develop the understanding of the aspirations, requirements and demands of both the local communities and the ecology of the area. The tangible and intangible aspects should be made an intrinsic part of the overall plan for the area. The policy making and management process should also integrate the tangible and intangible aspects. Conclusively, an integrated water resource planning is required to optimize the needs of the river-based settlement and it's ecosystem. Moreover, proper river management planning requires development of an institution that is responsible to deal with the task, which is multi-disciplinary and multi- dimensional.

\section{REFERENCES}

Ahmed, A., 2011, "Some of the Major Environmental Problems Relating to Land use Changes in the Coastal Areas of Bangladesh?: A Review", Journal of Geography \& Reg. Planning, 4:1-8.

Ahmed, Y., Choudhury, G. A., and Ahmed, M. S., 2017, "Strategy Formulation and Adaptation Pathways: Generation for Sustainable Development of Western Floodplain of Ganges", Journal of Water Resource and Protection, 9(6):663-691.

Ahmad, H., 2019, "Bangladesh Coastal Zone Management Status and Future Trends", Journal of Coastal Zone Management, 22(1): $1-7$.

CEGIS, (Centre for Environment and Geographic Information Services), 2012, "Master Plan of Haor Area", viewed 1411-2019, from https://www.undp.org/content/dam/bangladesh/docs/Projects/ncd-for-rioconvention/UNFCCC/National_Legislations/Master\%20Plan\%20of\%20Haor\%20Areas,\%20in\%202012\%20Volume\%20II.pdf 
Custers, P., 1993, “ Bangladesh's Flood Action Plan: A Critique”, Economic and Political Weekly, 28(29/30): 1501-1503.

Dempster, J. I. M., and Brammer, H., 1992, "Flood Action Plan - Bangladesh”, Outlook on Agriculture, 21(4): 301-305.

Department of Fisheries, 2017, "Yearbook of Fisheries Statistics of Bangladesh 2017-18", viewed 13-11-2019, from www.fisheries.gov.bd.

Dewan, C., Buisson, M. C., and Mukherji, A., 2014, “The Imposition of Participation? The Case of Participatory Water Management in Coastal Bangladesh", Water Alternatives, 7(2): 342-366.

EPWAPDA (East Pakistan Water and Power Development Authority), 1968, "Public Disclosure Authorized International Bank for Reconstruction and Development International Development Association", East Pakistan Water and Power Development Authority Food and Agriculture Organization, Government of East Pakistan International Engine.

Fang, Y., Ceola, S., Paik, K., Mc.Grath, G., Rao, P. S. C., Montanari, A., and Jawitz, J. W., 2018, “Globally Universal Fractal Pattern of Human Settlements in River Networks", Earth's Future, 6(8): 1134-1145.

GED (General Economics Division), 2018, “Bangladesh Delta Plan 2100 Baseline Study: Volume 1”, Planning Commission and Government of Bangladesh.

GOB, (Government of Bangladesh), 2013, "Bangladesh Water Act, 2013 (Act No. 14 of 2013)", viewed 22-10-2019, from https://www.ecolex.org/details/legislation/bangladesh-water-act-2013-act-no-14-of-2013-lex-faoc154320/

Hoque, S. F., Quinn, C., \& Sallu, S., 2018, "Differential Livelihood Adaptation to Social-Ecological Change in Coastal Bangladesh", Regional Environmental Change, 18(2): 451-463.

Hossain, M. K., 2016, "Bangladesh National Conservation Strategy", viewed 13-12-2019, from http://bforest.portal.gov.bd/sites/default/files/files/bforest.portal.gov.bd/notices/c3379d22_ee62_4dec_9e29_ 75171074d885/16.\%20Environmental,\%20Education\%20and\%20Awareness_NCS.pdf

Rudra, K., 2018, "Rivers of the Ganga-Brahmaputra-Meghna Delta: A Fluival Account of Bengal”, viewed 4-12-2019, from https://www.springer.com/gp/book/9783319765433

Sanwar, S., 2010, "Comparing Ecological Resource: Dependant Livelihood Patterns Between a Project and Non-Project Area", viewed 12-1-2020, fromhttp://lib.buet.ac.bd:8080/xmlui/handle/123456789/4194

Uddin, M. N., 2005, "Changes of Environmental Parameters Due to Salinity Intrusion in the Southwest Region of Bangladesh" viewed 15-1-2020, from http://lib.buet.ac.bd:8080/xmlui/handle/123456789/1751

WARPO, 2004a, "National Water Management Plan Approved", in WARPO Newsletter, pp. 1-8, viewed 13-2-2020, from http://www.warpo.gov.bd/pdf/newsletter7.pdf

WARPO, 2004b, "Bangladesh: Southwest Area Integrated Water Resources Planning and Management Project- Additional Financing," viewed 19-1-2020, from https://www.adb.org/projects/34418-023/main 